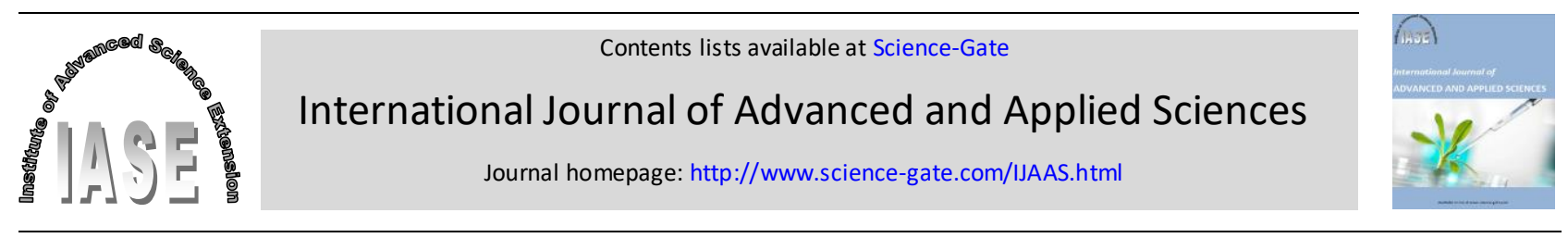

\title{
New modified direct torque control-fuzzy logic controller of doubly fed induction machine
}

\author{
Zemmit Abderrahim ${ }^{1, *}$, Messalti Sabir ${ }^{1}$, Abdelghani Harrag 2, 3 \\ ${ }^{1}$ Electrical Engineering Department, Faculty of Technology, Mohamed Boudiaf University, 28000 Msila, Algeria \\ ${ }^{2}$ CCNS Lab., Electronics Department, Faculty of Technology, Ferhat Abbas University, Cite Maabouda 19000 Setif, Algeria \\ ${ }^{3}$ Physics Department, Faculty of Sciences, Ferhat Abbas University, El-Bez 19000 Setif, Algeria
}

\section{A R T I C L E IN F O}

\section{Article history:}

Received 1 February 2017

Received in revised form

21 April 2017

Accepted 22 April 2017

Keywords:

Fuzzy logic controller

Double feed induction machine (DFIM)

Direct torque control DTC

Speed control

\begin{abstract}
A B S T R A C T
This paper presents a new modified direct torque control of doubly fed induction motor using fuzzy logic controller, which new fuzzy logic controller is used instead the classic integral proportional (IP or PI) controller. The validity of the proposed control algorithm is verified by simulation studies on a $0.8 \mathrm{~kW}$ DFIM system, which many parameters performances have been studied. The proposed fuzzy logic controller has shown better performances compared to the conventional PI controller overcoming their limitations and its implementation complexity.
\end{abstract}

(C) 2017 The Authors. Published by IASE. This is an open access article under the CC BY-NC-ND license (http://creativecommons.org/licenses/by-nc-nd/4.0/).

\section{Introduction}

Today, a great part of electrical energy is converted into mechanical energy using electrical motors. Among several types of motors, the doubly fed induction machine (DFIM) received a great attention as one of the most attractive solutions in both applications motor and generator. The DFIM has been selected for different applications such as: generator for renewable energy and motor for variable speed application, railway traction, marine propulsion, and hydroelectric power stations (Zemmit et al., 2016; Salloum, 2007).

Doubly-fed electric machine has many benefits over a conventional induction machine. Firstly, DFIM can operate in great range of speed variation around the synchronous speed. Secondly, DFIM parameters can be controlled easily (power flow, power factor). Thirdly, the cost of the converter is low when compared with other variable speed solutions because only a fraction of the mechanical power, typically $25-30 \%$, is fed to the grid through the converter, the rest being fed to grid directly from the stator. These advantages have encouraged numerous researchers to develop and improve it continuously. As consequence, DFIM control has known a great consideration and many control techniques have been proposed and validated experimentally, which the field oriented control (FOC) techniques have

\footnotetext{
* Corresponding Author.

Email Address: zemmit.mi@gmail.com (Z. Abderrahim) https://doi.org/10.21833/ijaas.2017.07.004

2313-626X/C 2017 The Authors. Published by IASE.

This is an open access article under the CC BY-NC-ND license

(http://creativecommons.org/licenses/by-nc-nd/4.0/)
}

been developed firstly. However, it highly dependent on the parameters of the induction machine and constant gains PI controllers may become unable to provide the required control performance. Hence, PI controller limitations and its complexity of implementation are the most drawbacks (Lekhchine et al., 2015; Biain and Vidal, 2008). Direct torque control (DTC) introduced in 1980s (Takahashi and Ohmori, 1989) has provided more performances which an appropriate voltage vector is selected based on stator flux and torque information; then the direct self-control (DSC) method proposed by Depenbrock (1988) demonstrated better steadystate and transient torque control conditions rather than FOC techniques.

Many modifications and improvements have been introduced to direct control techniques to reduce torque ripple (Flach et al., 1997) and achieved constant switching frequency such as direct mean torque control (DMTC) (Boulouiha et al., 2015) direct torque control using artificial neural network (DTC-ANN). In addition, many intelligent control strategies have been proposed such as adaptive fuzzy vector controller (AFVC), fuzzy logic control (FLC) (Bouafia et al., 2009; Lai and Lin, 2003) sliding mode control (SMC) (Medjber et al., 2016) back stepping control, Fuzzy-SVM, etc.

In this paper, to reduce the dip in the speed, new fuzzy controller for DTC of doubly fed induction machine DFIM has been developed. Modelling of DFIM and details of proposed control strategy has been presented. The performances in terms of torque, speed tracking and accuracy have been demonstrated using 0.8kW DFIM. 


\section{Doubly fed induction machine model}

The state-all-flux DFIM dynamic model expressed in $(\alpha, \beta)$ axes rotational reference frame is given by the following equations (Eqs. 1 and 2):

$$
\begin{gathered}
\left\{\begin{array}{c}
V_{s \alpha}=R_{s} I_{s \alpha}+\frac{d}{d t} \Phi_{s \alpha} \\
V_{s \beta}=R_{s} I_{s \beta}+\frac{d}{d t} \Phi_{s \beta} \\
V_{r \alpha}=R_{r} I_{r \alpha}+\frac{d}{d t} \Phi_{r \alpha}+\omega \Phi_{r \beta} \\
V_{r \beta}=R_{r} I_{r \beta}+\frac{d}{d t} \Phi_{r \beta}+\omega \Phi_{r \alpha}
\end{array}\right. \\
\left\{\begin{array}{l}
\Phi_{s \alpha}=I_{s} I_{s \alpha}+M I_{r \alpha} \\
\Phi_{s \beta}=I_{s} I_{s \beta}+M I_{r \beta} \\
\Phi_{r \alpha}=I_{r} I_{r \alpha}+M I_{s \alpha} \\
\Phi_{r \beta}=I_{r} I_{r \beta}+M I_{s \beta}
\end{array}\right.
\end{gathered}
$$

the electromagnetic torque is given by (Eq. 3):

$$
C_{e m}=\frac{3 p M}{2 L_{s}}\left(\Phi_{s \alpha} I_{r \beta}-\Phi_{s \beta} I_{r \alpha}\right)
$$

\section{Direct torque control of DFIM}

DTC is an advanced control method involving direct control of the electromagnetic torque and the flux developed in the double feed induction machine. The heart of the control system in the DTC is the flux and torque hysteresis controllers and an optimal switching state logic block. An appropriate DFIM model is essential for the correct estimation of the electromagnetic torque and stator flux. The estimation of these quantities is carried out by measurements of the DFIM currents, flux linkages and the DC voltage. The estimated values of the motor torque and flux are inputs to the two hysteresis controllers wherein, a comparison between the estimated and the actual values of the quantities is performed (Naveen et al., 2013).

Direct torque control is based on the flux orientation, using the instantaneous values of voltage vector. An inverter provides eight voltage vectors, among which two are zeros. These vectors are errors as well as the stator flux vector chosen from a switching table according to the flux and torque position. In this technique, we don't need the rotor position in order to choose the voltage vector. This particularity defines the DTC as an adapted control technique of AC machines and is inherently a motion sensorless control method (Biain and Vidal, 2008). As shown in Fig. 1, the position vectors and status of the flux and torque, the stator flux is divided into six sectors. There are also 8 voltage vectors which correspond to possible inverter states. The flux estimator can be obtained by (Eq. 4):

$\overline{\emptyset_{s}}(t)=\int_{0}^{t}\left(\overline{V_{s}}-R_{S} \bar{I}_{s}\right) d t$

The stator flux $\emptyset_{\text {sref }}$ and the torque Cemref $_{\text {ref }}$ are compared with respective estimated values, and errors are processed through hysteresis-band controllers. The digital outputs from the hysteresis comparators along with the sector number are shown in Table 1. The correct voltage vector is then

\begin{tabular}{|c|c|c|c|c|c|c|c|c|}
\hline Flux & Couple & $N=1$ & $N=2$ & $N=3$ & $N=4$ & $N=5$ & $N=6$ & Corrector \\
\hline \multirow{3}{*}{$C f l x=0$} & Ccpl=1 & $V_{3}$ & $V_{4}$ & $V_{5}$ & $V_{6}$ & $V_{1}$ & $V_{2}$ & \multirow{2}{*}{2 levels } \\
\hline & Ccpl=0 & $V_{4}$ & $V_{5}$ & $V_{6}$ & $V_{1}$ & $V_{2}$ & $V_{3}$ & \\
\hline & Ccpl=-1 & $V_{5}$ & $V_{6}$ & $V_{1}$ & $V_{2}$ & $V_{3}$ & $V_{4}$ & 3 levels \\
\hline \multirow{3}{*}{$C f l x=1$} & Ccpl=1 & $V_{2}$ & $V_{3}$ & $V_{4}$ & $V_{5}$ & $V_{6}$ & $V_{1}$ & \multirow{2}{*}{2 levels } \\
\hline & Ccpl $=0$ & $V_{1}$ & $V_{2}$ & $V_{3}$ & $V_{4}$ & $V_{5}$ & $V_{6}$ & \\
\hline & Ccpl=-1 & $V_{6}$ & $V_{1}$ & $V_{2}$ & $V_{3}$ & $V_{4}$ & $V_{5}$ & 3 levels \\
\hline
\end{tabular}
selected. The corresponding switch position for the inverter, to achieve the selected voltage vector is shown in Table 2.

Table 2: Switch positions and their voltage vectors

\begin{tabular}{ccccccccc}
\hline & $\mathrm{V}_{0}$ & $\mathrm{~V}_{1}$ & $\mathrm{~V}_{2}$ & $\mathrm{~V}_{3}$ & $\mathrm{~V}_{4}$ & $\mathrm{~V}_{5}$ & $\mathrm{~V}_{6}$ & $\mathrm{~V}_{7}$ \\
\cline { 2 - 9 } $\mathrm{S}_{\mathrm{a}}$ & 0 & 1 & 1 & 0 & 0 & 0 & 1 & 1 \\
$\mathrm{~S}_{\mathrm{b}}$ & 0 & 0 & 1 & 1 & 1 & 0 & 0 & 1 \\
$\mathrm{~S}_{\mathrm{c}}$ & 0 & 0 & 0 & 0 & 1 & 1 & 1 & 1 \\
\hline
\end{tabular}

the theory of fuzzy sets developed by Zadeh (Holakooie et al., 2016; Ouledali et al., 2015). The proposed fuzzy controller has two inputs and one output as described in Fig. 2.

The choice of the zero vectors $\left(\mathrm{V}_{0}, \mathrm{~V}_{7}\right)$ produces a smaller torque and flux variations compared with the active vectors. Then, the zero vectors are not really needed to keep the torque and flux controlled. However, it is used to reduce the torque and flux ripples at steady state operation. For almost every application of DTC, it is advantageous if the torque and flux ripples are minimized as much as possible (Pura and Iwanski, 2014).

\section{Fuzzy speed controller}

In order to eliminate the speed static error, while keeping the stability of system, the motor speed can be controlled indirectly by controlling the torque with a fuzzy controller. The Fuzzy Logic is based on

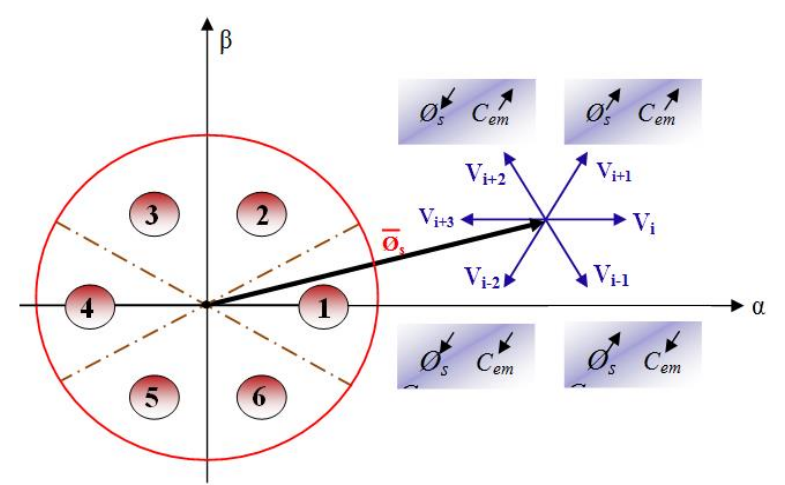

Fig. 1: Vectors and Status of the flux and torque

Where e is the error, expressed by Eq. 5 and $d e$ is derived from the error approximated by Eq. 6 with T the sampling period. The output of the regulator is given by Eq. 7 . 


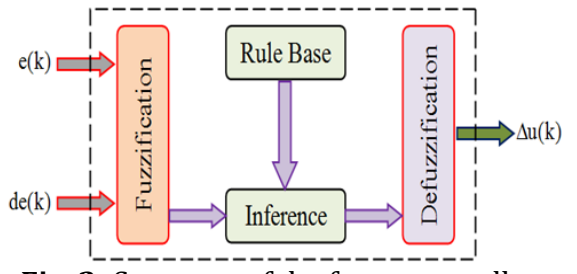

Fig. 2: Structure of the fuzzy controller

$e(k)=\omega^{*}(k)-\omega(k-1)$

de $=\frac{e(k)-(e(k-1)}{T}$

$C_{r e f}(k)=C_{r e f}(k-1)+\Delta u(k)$

The fuzzy controller is composed of three blocks: fuzzification, rule bases, and de-fuzzification. Fig. 3a shows the membership function of input signals $(e$, de); while Fig. 3b shows the membership functions of output signal

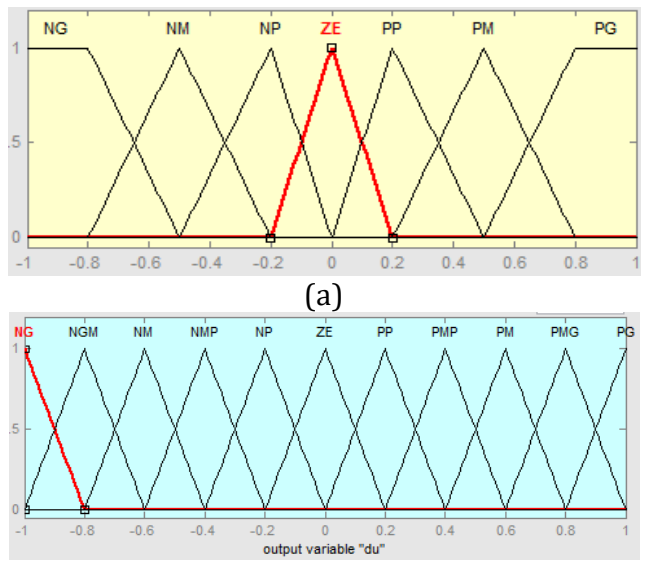

(b)

Fig. 3: The membership function

There are 7 fuzzy subsets for each input variable, which gives $7^{*} 7=49$ possible rules. The rules base is shown in Table 3. Fig. 4 shows the corresponding control surface of the proposed FLC controller.

Table 3: Rules base

\begin{tabular}{|c|c|c|c|c|c|c|c|}
\hline & NG & NM & NP & $\mathrm{ZE}$ & PP & PM & $P G$ \\
\hline NG & $\mathrm{NG}$ & $\mathrm{NG}$ & NGM & $\mathrm{NM}$ & NMP & NP & ZE \\
\hline $\mathrm{NM}$ & NG & NGM & NM & NGM & NP & $\mathrm{ZE}$ & PP \\
\hline NP & NGM & NM & NMP & NP & ZE & PP & PMP \\
\hline $\mathrm{ZE}$ & NM & NMP & NP & ZE & PP & PMP & PM \\
\hline PP & NMP & NP & ZE & PP & PMP & PM & PMG \\
\hline PM & NP & ZE & PP & PMP & PM & PMG & PG \\
\hline PP & $\mathrm{ZE}$ & PP & PMP & PM & PMG & PG & PG \\
\hline
\end{tabular}

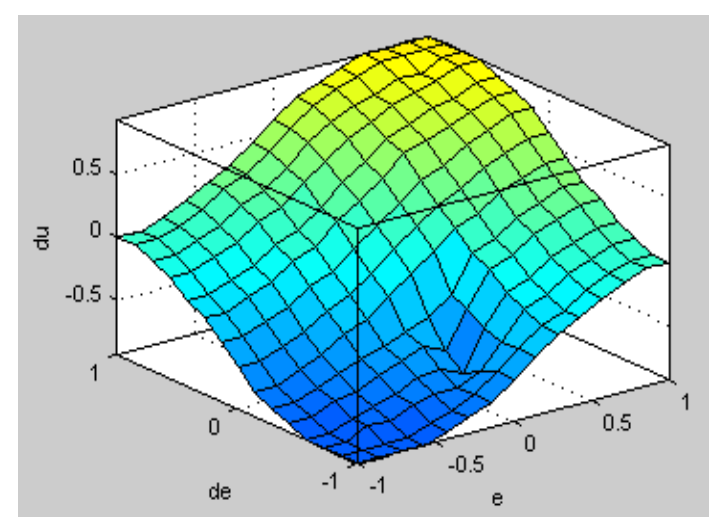

Fig. 4: FLC control surface
The proposed FLC speed controller is shown in Fig. 5. The weights are determined by training algorithm.

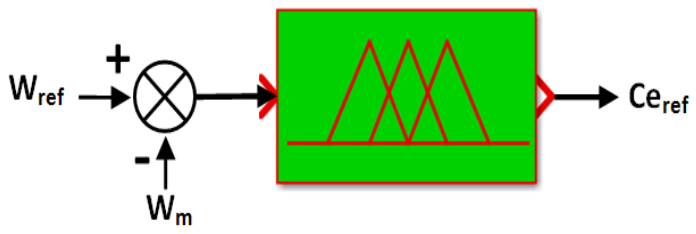

Fig. 5: The fuzzy logic speed controller

The proposed DTC-FLC scheme including both Fuzzy logic speed controller is illustrated in the Fig. 6.

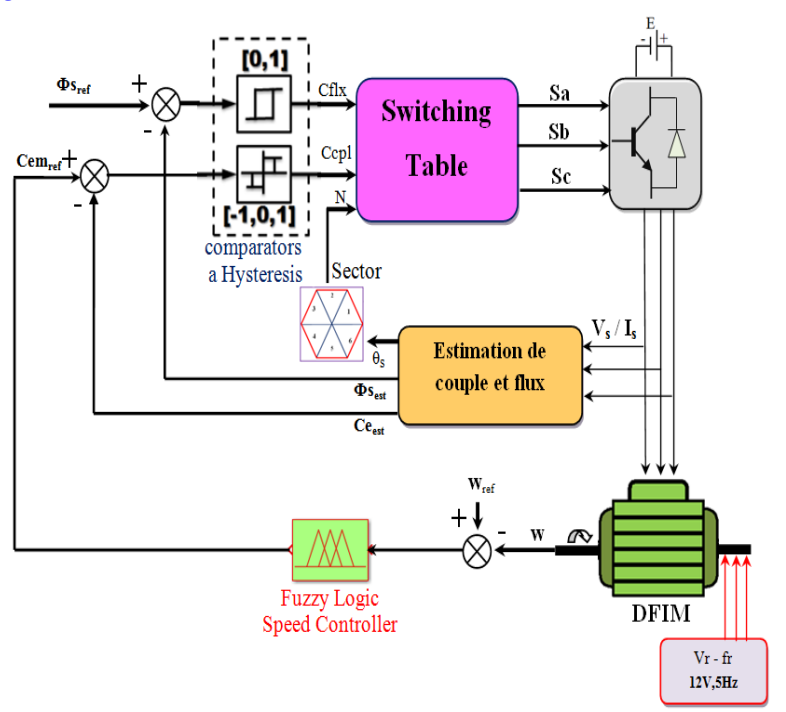

Fig. 6: DTC-FLC scheme

\section{Simulation results}

To demonstrate the efficiency of the proposed DTC-FLC strategy, simulations results have been carried out using $0.8 \mathrm{~kW}$ DFIM with the following parameters (Zemmit and Messalti, 2016), which many performance parameters have been studied:

$P_{n}=0.8 \mathrm{~kW} ; U_{n}=220 / 380 \mathrm{~V} ; \mathrm{F}=50 \mathrm{~Hz} ; \mathrm{I}=3.8 / 2.2 \mathrm{~A}$

$V r=3 \times 120 \mathrm{~V} ; 4.1 \mathrm{~A} ; \Omega=1420 \mathrm{tr} / \mathrm{min} ; R s=11.98 \Omega$;

$R r=0.904 \Omega ; L s=0.414 H ; L r=0.0556 H ; M=0.126 H ; P=2$; $J=0.01 \mathrm{~kg} \cdot \mathrm{m}^{2} ; f=0.001$

The developed DTC-FLC-DFIM Simulink model is presented in Fig. 7.

The simulation results obtained with no load as starting up condition and connecting the nominal load as normal operating condition are presented in following figures. Figs. 8 and 9 illustrate the speed and electromagnetic torque respectively; while Fig. 8 shows the corresponding flux.

From Fig. 8, we can see that at starting up with no load or in case of nominal load, the DTC-FLC controller reaches its speed reference rapidly without overshoot. So the excellent dynamic performance of torque and flux control is evident.

From Fig. 9, it is clear that the electromagnetic torque obtained by proposed DTC-FLC show better performances characterized by less response time 
and low overshoot. The stator flux circle is shown in Fig. 10. Fig. 11 shows the static phase current issued by DTC-FLC of DFIM.

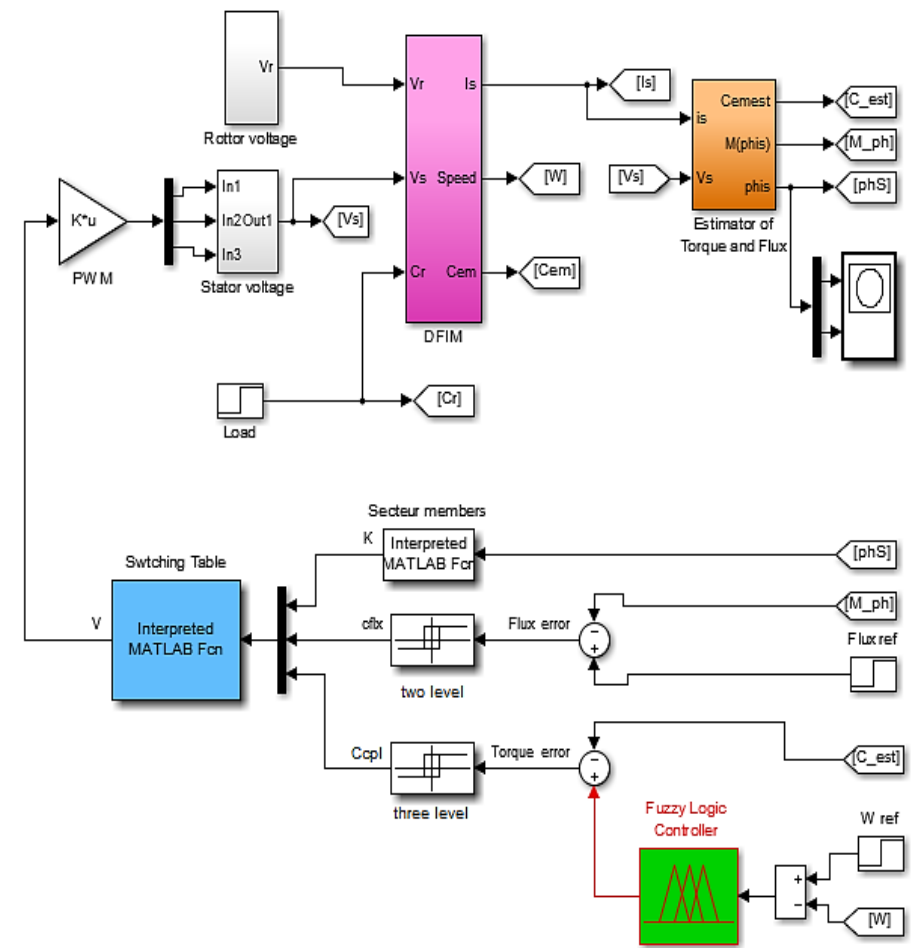

Fig. 7: The developed Simulink model of hybrid Direct Torque Control-Fuzzy logic controller (DTC-FLC) applied on DFIM

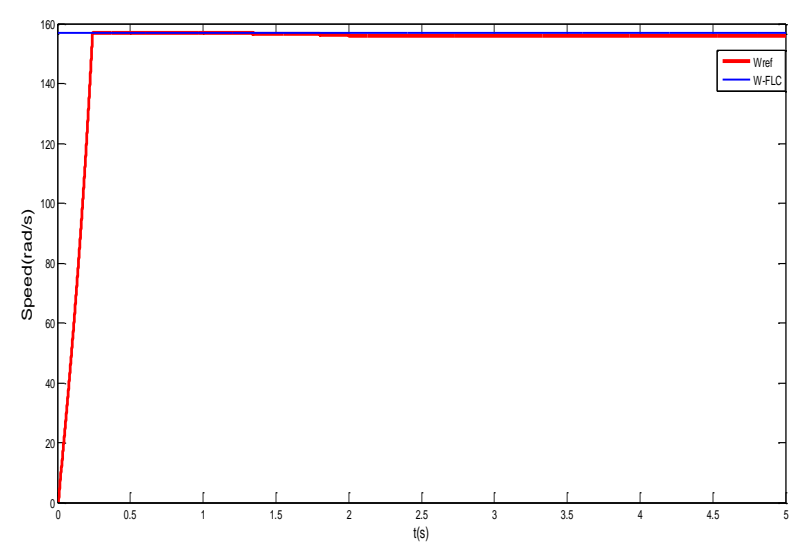

Fig. 8: DTC-FLC under speed variation

From Figs. 8, 9, 10, and 11, the control performances are very satisfactory. The dynamics of continuation is not affected during the variation of the load torque. The rejection of disturbance is very efficient. We notice for speed a fast starting without an overshoot and static error. The stator flux vector locations figure describes the stator flux vector trajectory which is circular.

\section{Conclusion}

A new hybrid direct torque control strategy-fuzzy logic controller (DTC-FLC) for DFIM has been proposed and investigated in this paper. Modelling of DFIM and proposed DTC-FLC strategy including the development fuzzy logic controller (structure, function, rules) has been discussed in detail. Simulation results demonstrate the effectiveness and the robustness of the proposed DTC-FLC. In addition, in most of the previously published paper DTC applications on DFIM uses PI or IP in speed control loop, however their limitations and their complexity of implementation are the most drawbacks. Thus, using the proposed DTC-FLC, previous mentioned drawbacks will be disappeared.
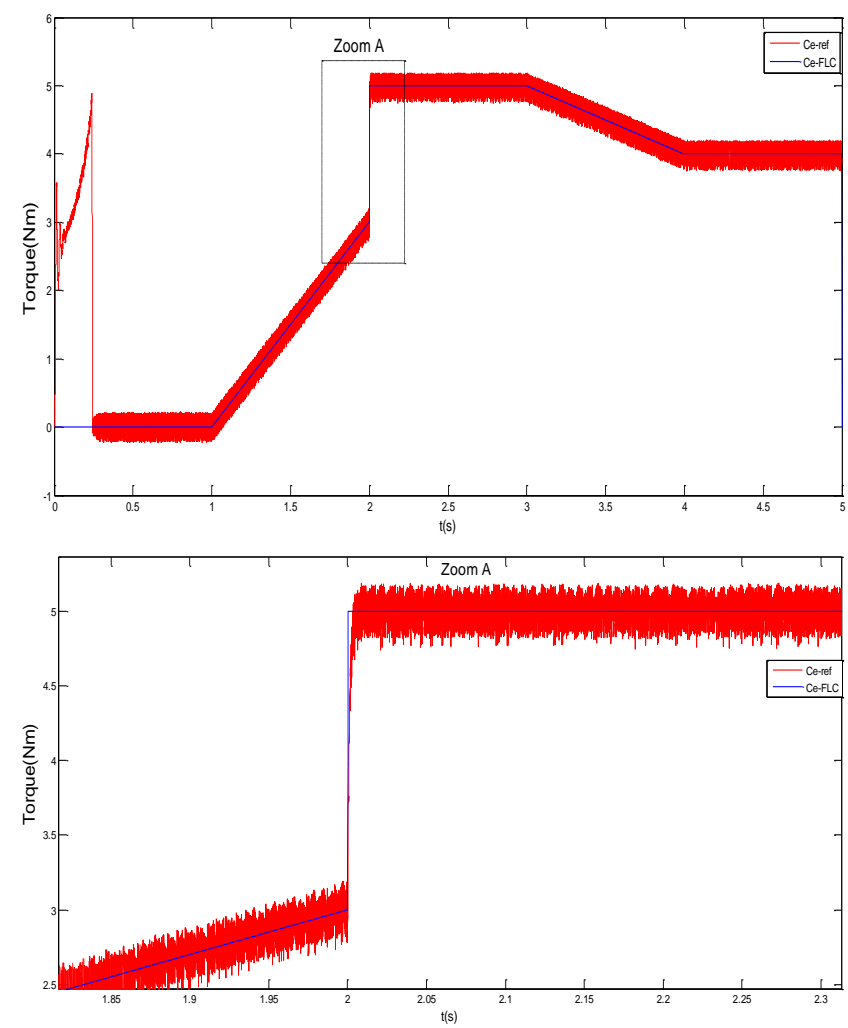

Fig. 9: DTC-FLC under variable load 


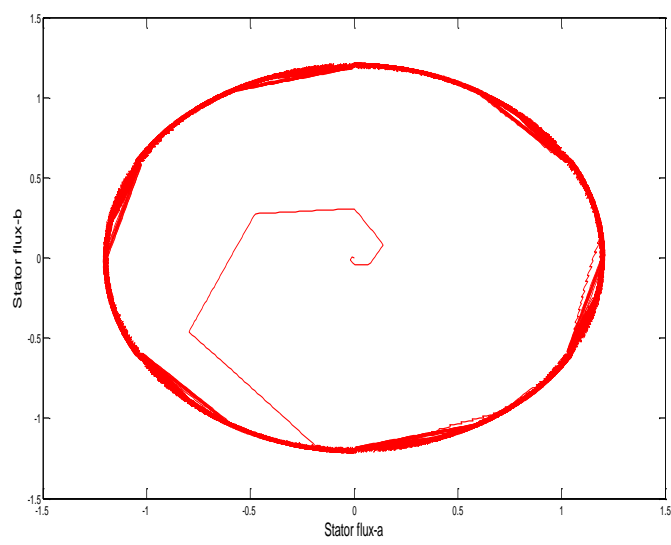

Fig. 10: Stator flux circle
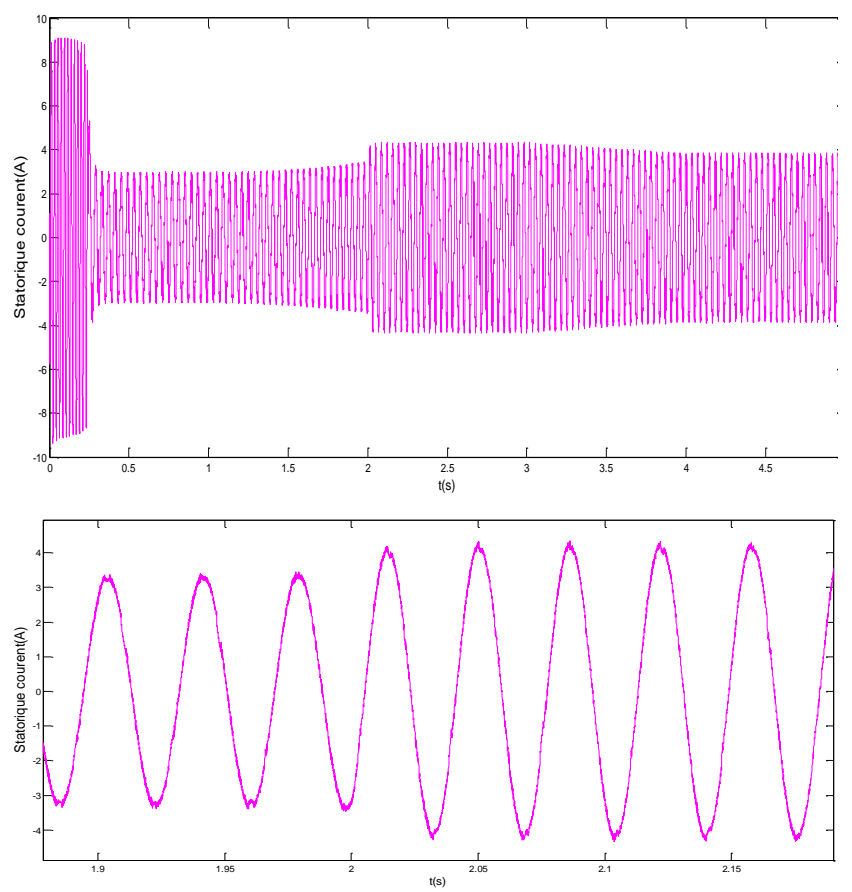

Fig. 11: Stator current of DFIM using DTC-FLC

\section{References}

Biain GA and Vidal DMÁR (2008). Predictive direct control techniques of the doubly fed induction machine for wind energy generation applications. Ph.D. Dissertation, Mondragon University, Mondragon, Spain.

Bouafia A, Krim F, and Gaubert JP (2009). Design and implementation of high performance direct power control of three-phase PWM rectifier, via fuzzy and PI controller for output voltage regulation. Energy Conversion and Management, 50(1): 6-13.
Boulouiha HM, Allali A, Laouer M, Tahri A, Denai M, and Draou A (2015). Direct torque control of multilevel SVPWM inverter in variable speed SCIG-based wind energy conversion system. Renewable Energy, 80: 140-152.

Depenbrock M (1988). Direct self-control (DSC) of inverter-fed induction machine. IEEE Transactions on Power Electronics, 3(4): 420-429.

Flach E, Hoffmann R, and Mutschler P (1997). Direct mean torque control of an induction motor. In the $7^{\text {th }}$ European Conference on Power Electronics and Applications (EPE'97), 3: 672-677.

Holakooie MH, Ojaghi M, and Taheri A (2016). Full-order Luenberger observer based on fuzzy-logic control for sensorless field-oriented control of a single-sided linear induction motor. ISA Transactions, 60: 96-108.

Lai YS and Lin JC (2003). New hybrid fuzzy controller for direct torque control induction motor drives. IEEE Transactions on Power Electronics, 18(5): 1211-1219.

Lekhchine S, Bahi T, Abadlia I, Layate Z, and Bouzeria H (2015). Speed control of doubly fed induction motor. Energy Procedia, $74,575-586$.

Medjber A, Guessoum A, Belmili H, and Mellit A (2016). New neural network and fuzzy logic controllers to monitor maximum power for wind energy conversion system. Energy, 106: $137-146$.

Naveen G, Sarvesh PKS, and Krishna BR (2013). DTC control strategy for doubly fed induction machine. International Journal of Engineering and Advanced Technology (IJEAT), 3(1): 92-95.

Ouledali O, Meroufel A, Wira P, and Bentouba S (2015). Direct torque fuzzy control of PMSM based on SVM. Energy Procedia, 74: 1314-1322.

Pura P and Iwanski G (2014). Direct power control with referenced torque and reactive power of Doubly Fed induction machine connected to unbalanced grid. In the $9^{\text {th }}$ International Conference on Ecological Vehicles and Renewable Energies (EVER), IEEE, Monte-Carlo, Monaco: 1-6. https://doi.org/10.1109/EVER.2014.6844011

Salloum G (2007). Contribution at the robust control of doubly fed induction motor. Ph.D. Dissertation, National Institute Polytechnic of Toulouse, France.

Takahashi I and Ohmori Y (1989). High-performance direct torque control of an induction motor. IEEE Transactions on Industry Applications, 25(2): 257-264.

Zemmit A and Messalti S (2016). Modeling and simulation of doubly fed induction motor (DFIM) control using DTC and DFOC: A comparative study. International Journal of Applied Engineering Research, 11(8): 5623-5628.

Zemmit A, Messalti S, and Harrag A (2016). Innovative improved Direct torque control of doubly fed induction machine (DFIM) using artificial neural network (ANN-DTC). International Journal of Applied Engineering Research, 11(16): 9099-9105. 